\title{
Formação continuada: um estudo colaborativo com professores do Ensino Médio de Rondônia
}

\section{Continuing education: a collaborative study with Rondônia High School's teachers
Formación continua: un estudio en colaboración con profesores de Secundaria que sean de Rondônia

\author{
Sirley Leite Freitas ${ }^{1}$ \\ Juracy Machado Pacífico
}

Recebido em 27/04/2018; revisado e aprovado em 04/06/2018; aceito em: 26/07/2018.

DOI: http://dx.doi.org/10.20435/inter.v21i1.1953

\begin{abstract}
Resumo: Este artigo resulta de recorte de uma pesquisa de mestrado. Aqui, apresentamos o resultado da investigação dos desafios e das possiblidades para efetivar a formação continuada, dentro do espaço escolar, para professores do ensino médio. Participaram da pesquisa 16 professores e quatro membros da equipe pedagógica de uma escola da rede estadual de ensino em Rondônia. Após o estudo, podemos afirmar que efetivar a formação continuada dentro do espaço escolar é algo possível, desde que se reflita e construa coletivamente todo o processo.
\end{abstract}

Palavras-chave: educação; formação docente; formação continuada; desafios da formação.

Abstract: This article results from a master's research cut-off. Here, we present the result of the investigation of the challenges and possibilities to carry out the continuous training, within the school space, for high school teachers. Participated in the research 16 teachers and four members of the pedagogical team of a school of the state education network in Rondônia. After the study, we can affirm that carrying out the continuous formation within the school space is something possible, as long as the whole process is reflected and constructed collectively.

Keywords: education; teacher training; continuing education; challenges of training.

Resumen: Este artículo resulta de recorte de una investigación de maestría. Aquí presentamos el resultado de la investigación de los desafíos y posibilidades para efectivizar la formación continuada, dentro del espacio escolar, para profesores de enseñanza media. Participaron de la investigación 16 profesores y cuatro miembros del equipo pedagógico de una escuela de la red estatal de enseñanza en Rondônia. Después del estudio podemos afirmar que hacer efectiva la formación continuada dentro del espacio escolar es algo posible desde que se refleja y construye colectivamente todo el proceso.

Palabras clave: educación; la formación del profesorado; educación continua; desafíos de la formación.

\section{INTRODUÇÃO}

Nos últimos anos, em nosso trabalho docente, temos presenciado a angústia de professores que atuam no ensino médio e afirmam ter a necessidade de uma formação continuada que possa embasar seu trabalho diante das constantes mudanças e demandas educacionais. A Lei Federal n. 9.394/96 (BRASIL, 1996) preceitua isso quando dispõe sobre a formação continuada, mas não somente a legislação federal, também os entes federados apresentam em suas legislações a necessidade de formação continuada, como é o caso da Lei n. 680/2012 do Estado de Rondônia. Porém, como afirmam os teóricos Gadotti (2011), Imbernón (2009; 2011), Libâneo (2004), Nóvoa (2001; 2009), Perrenoud (2000; 2001) e Pimenta (2000), a formação continuada ainda é um desafio para muitos professores e para o sistema educacional.

\footnotetext{
$\overline{{ }^{1} \text { Instituto Federal }}$ de Educação, Ciências e Tecnologia de Rondônia (IFRO), Porto Velho, Rondônia, Brasil.

${ }^{2}$ Fundação Universidade Federal de Rondônia (UNIR), Porto Velho, Rondônia, Brasil.
} 
Por compreender a complexidade desta temática dentro do espaço escolar, este estudo buscou investigar quais são os desafios e as possibilidades para efetivar a formação continuada dos professores que atuam no ensino médio em uma escola da rede estadual em Rondônia, para então propor junto aos professores e à equipe pedagógica da escola a elaboração coletiva de um plano de ação que pudesse contribuir com a efetivação da formação continuada dentro do espaço escolar.

\section{FORMAÇÃO CONTINUADA: CONCEPÇÕES, DESAFIOS E POSSIBILIDADES}

Hoje se discutem outras concepções pedagógicas, além das concepções tradicionais. Essas novas discussões trazem consigo outras formas de desenvolver a formação inicial e continuada dos professores.

Na década de 1970, os cursos de formação se preocupavam mais com o método de treinamento dos professores, uma vez que os currículos eram mais focados nas dimensões técnicas. $E$, a partir da década de 1980, perceberam-se as primeiras críticas a essa visão focada somente na técnica, principalmente aos programas de formação conhecidos como treinamentos em serviço ou reciclagem. Esses cursos eram considerados insuficientes para atender os reais problemas enfrentados pelos professores e não havia uma continuidade na formação (PEREIRA, 2007).

Neste sentido, Silva (2007, p. 105) acrescenta que:

Apesar dos avanços ocorridos na década de 1990, quanto à forma de conceber a formação continuada de professores, grande parte dos programas de formação do Brasil ainda vem se pautando em uma tendência liberal-conservadora, inspirada numa perspectiva homogeneizadora, autoritária, instrumental e de base acadêmica e teórica [...]. Nessa concepção, o professor é reduzido a reprodutor de conhecimentos já instituídos, cumprindo apenas os programas decididos por especialistas que nem sequer conhecem a realidade cotidiana da escola.

A formação continuada em uma nova vertente vem sendo discutida com mais ênfase no Brasil desde os anos 1980 (BRASIL, 2002). Com a promulgação da Constituição Federal de 1988 e da Lei n. 9394/96, Lei de Diretrizes e Bases da Educação Nacional (LDBEN), muitas políticas públicas educacionais foram implantadas na tentativa de melhorar a qualidade do ensino no Brasil. Entre elas, algumas destinadas à formação continuada, atendendo ao disposto nos parágrafos 1 으 e 2 ㅇ do art. 62, parágrafo único do art. 62A e no art. 63, III da lei n. 9.394/96. No mesmo sentido, dispõem o parágrafo 4o do art. 66 da Lei n. 680/2012 do Estado de Rondônia:

$\S 4$. A jornada de 40 (quarenta) horas semanais do Professor Classe "B" e "C", do 6o ao 9o ano do Ensino Fundamental e do Ensino Médio, em função docente, inclui 27 (vinte e sete) horas em atividade docente, 05 (cinco) horas de planejamento na escola e 08 (oito) horas destinadas à formação continuada e/ou atividades independentes. (RONDÔNIA, 2012)

Mesmo sendo um direito, não é algo comum para grande parte dos professores brasileiros. "Alguns municípios têm legislado garantindo o direito à formação continuada de professores, mas, na prática, a oferta e a qualidade da mesma não satisfazem nas diversas partes relacionadas" (PRADA, 2007, p. 111).

Os referenciais para formação de professores apontam que a organização e a promoção da formação continuada são primordialmente papel das secretarias de Educação, pois são elas que podem acompanhar de forma sistemática o desenvolvimento de diretrizes, eventos e programas 
de formação continuada (BRASIL, 2002). Portanto a efetivação da formação continuada ainda é um processo complexo, e todo processo complexo demanda certo tempo para a consolidação.

A formação continuada não é uma invenção nova, mas é algo ainda frágil nos dias atuais e, dentro das novas perspectivas, busca não somente o aprimoramento dos conhecimentos adquiridos na formação inicial, mas também uma identidade para o professor (PERRENOUD, 2000).

Em relação à formação continuada, Libâneo (2004, p. 227) destaca que:

O termo formação continuada vem acompanhado de outro, a formação inicial. A formação inicial refere-se ao ensino de conhecimentos teóricos e práticos destinados à formação profissional, completados por estágios. A formação continuada é o prolongamento da formação inicial, visando o aperfeiçoamento profissional teórico e prático no próprio contexto de trabalho e o desenvolvimento de uma cultura geral mais ampla, para além do exercício profissional.

Segundo Rodrigues (1998), o professor não está preparado porque cursou a faculdade, pois se exige dele um crescimento de sua consciência política na atuação pedagógica e, para isso, deve estar em constante transformação e compromisso com sua competência técnica.

Freire (2011) afirma que o professor deve ter clareza de sua prática pedagógica e que isso demanda amplo conhecimento das diferentes dimensões que qualificam a prática pedagógica; para tanto, é necessário aprender, e aprender é construir, refletir e mudar.

Gadotti (2011, p. 41), na mesma perspectiva freireana, entende que:

A formação continuada do professor deve ser concebida como reflexão, pesquisa, ação, descoberta, organização, fundamentação, revisão e construção teórica e não como mera aprendizagem de novas técnicas, atualização em novas receitas pedagógicas ou aprendizagem das últimas inovações tecnológicas. A nova formação permanente, segundo essa concepção, inicia-se pela reflexão crítica sobre a prática.

Entretanto essa mudança na prática pedagógica não é algo que acontece com facilidade e muitos educadores relutam em mudar. Neste sentido, Santos (2002, p. 29) afirma que "o pensamento tradicional e o posicionamento didático mecanicista e tecnicista permaneceu no Brasil por muitas décadas e ainda está presente nas práticas pedagógicas em muitas escolas".

Pesquisas apontam que os grandes desafios da formação continuada é a fragmentação dos estudos ou programas de formação oferecidos e a grande rotatividade de gestores pedagógicos, administrativos e professores. Já os professores indicam que os grandes problemas para a efetivação de uma formação continuada que surta resultados são a pouca sintonia entre a formação continuada e as reais necessidades a que são submetidos, a não participação dos professores nas decisões, falta de acompanhamento sistematizado da prática pedagógica, descontinuidade de políticas públicas direcionadas à formação continuada e baixos salários que levam a uma dupla carga horária.

Outro problema detectado em pesquisas sobre a formação continuada é a imposição de curso aos professores sem que estes sejam consultados sobre as reais necessidades e por vezes essa imposição provoca rejeição dos programas por parte dos professores (GATTI; BARRETO, 2009).

Imbernón (2011) entende ser um desafio para a efetivação da formação continuada as seguintes situações: o predomínio da improvisação; a definição de objetivos contraditórios que ora visam à prática ora à teoria; a falta de autonomia das instituições para realizarem a formação continuada em seu espaço escolar; sobrecarga de trabalho dos professores e demais profissionais 
da educação; a falta de formadores bem capacitados; a formação desenvolvida em contextos personalistas e individualistas; e o fato de se ver a formação exclusivamente como meio de incentivo salarial e de promoção.

Para alguns educadores, o melhor espaço para realizar a formação continuada é a própria escola, pois

No exercício da profissão, cumpre-se faça a formação nos seus próprios lugares e tempos; no caso do educador, o tempo-espaço mais específico da sala de aula e da escola. Este é o mundo de referência de todo o processo formativo. Em todas as suas instâncias, quer nas preparatórias, quer nas que se seguem a título de formação continuada, tudo se deve organizar e conduzir em função do ensino-aprendizagem mediado pela docência e pela escola. (MARQUES, 2000, p. 206)

Quando os professores reelaboram os seus saberes adquiridos na formação inicial, interligando-os com as experiências de suas práticas docentes, a formação pode ser entendida como autoformação. E, nesse processo de vivenciar a teoria da formação inicial e a prática do cotidiano escolar de uma forma dialética, o professor pode criar com seus pares, coletivamente, a construção de novos saberes. A formação deve ser pensada como um projeto único que globaliza a formação inicial e a formação continuada, de maneira que envolve a formação autônoma dos professores e a reelaboração contínua de novos saberes, partindo da vivência prática e das experiências obtidas do espaço escolar (PIMENTA, 2000).

Para que a formação continuada seja efetivada, o professor deve estar comprometido com sua formação, pois, para que esta reflita na prática pedagógica, é necessária a reflexão de sua prática. Nesse sentido, Freire (2011, p. 40) corrobora dizendo que "na formação permanente dos professores, o momento fundamental é o da reflexão crítica sobre a prática. É pensando criticamente a prática de hoje ou de ontem que se pode melhorar a próxima prática".

Ao entender a escola como o espaço mais apropriado para a formação continuada do professor, deve-se fortalecê-la como ambiente pedagógico onde prática e teoria se fundem para produzir o conhecimento. A sala de aula é o lugar onde surgem os problemas e onde a reflexão deve ser feita e, se for feita uma reflexão coletiva de teorias e práticas, de conhecimentos e saberes diversos, haverá uma reconstrução de saberes e uma construção de novos saberes, fazendo com que se melhore o processo de ensino-aprendizagem, a prática pedagógica e o próprio saber pedagógico (MARQUES, 2000).

A qualificação do professor vai além de um conjunto de técnicas e teorias, perpassa a prática e chega a uma dimensão política-pedagógica; na busca da qualidade de ensino, a qualificação do professor é primordial, mas sua efetivação extrapola as questões pedagógicas e atinge questões socioeconômicas e políticas (AZZI, 2000). Segundo Nóvoa (2001, p. 12), “o aprender contínuo é essencial em nossa profissão. Ele deve se concentrar em dois pilares: a própria pessoa do professor, como agente, e a escola, como lugar de crescimento profissional permanente", ou seja, a escola é o lugar ideal para efetivação da formação continuada.

Na busca da reflexão entre a prática e a teoria, Imbernón (2009) assevera que a troca de experiências entre os professores pode ser o caminho e que, como a troca de experiências faz com que um professor aprenda com o outro, isso os leva à resolução de problemas comuns a todos.

O professor tem na escola o espaço ideal para a tomada de decisões, mas isso não significa que somente a qualificação do professor seria o único paliativo para melhoria da educação, principalmente porque há hoje uma política de desvalorização do profissional da educação, 
em que professores são mal pagos, a carga horária é extensa, entre outros problemas. Mesmo com todas as dificuldades, é mais eficaz buscar a qualificação dos professores que aí estão, por meio da formação continuada, e investir na formação dos futuros professores para melhorar a educação (AZZI, 2000).

Investir na qualificação do professor pode não ser a solução para os problemas da educação brasileira, mas não se pode falar em educação de qualidade composta por profissionais desqualificados, malpreparados e desatualizados.

\section{PROCEDIMENTOS METODOLÓGICOS}

Em termos metodológicos, o presente estudo, de abordagem qualitativa, foi desenvolvido por meio da pesquisa-ação. A pesquisa qualitativa foi a basilar, haja vista o método utilizado para a qualificação dos dados coletados durante a realização da pesquisa e análise dos dados. Também foi primordial a experiência dos sujeitos e a generalização derivada da análise documental e entrevista realizadas (THIOLLENT, 2005).

Visando atingir aos objetivos definidos, a pesquisa foi desenvolvida com 16 professores que atuam no ensino médio e membros da equipe pedagógica (diretor, vice-diretor, supervisor e orientador) de uma escola da rede estadual de ensino no Estado de Rondônia.

Compreendendo que o objeto de estudo é a formação continuada dos professores de ensino médio, os instrumentos basilares de coleta de dados foram os questionários e a entrevista semiestruturada baseada nos conceitos aplicados por Gil (1999).

O intuito dos questionários e das entrevistas foi o de compreender como vinha sendo executada a formação continuada para professores na escola acima citada e de levantar os problemas enfrentados pelos professores e pela equipe pedagógica da escola para realização da formação continuada dentro do espaço escolar. Buscamos coletar dados relativos a se os professores mantiveram uma formação contínua após o término da formação inicial. Além disso, buscamos também: verificar com que frequência isso ocorria; se receberam algum tipo de formação oferecida pelo poder público e/ou pela escola onde trabalham; se os cursos oferecidos eram em suas áreas de formação; se havia uma continuidade nos cursos; se eram consultados sobre quais tipos de cursos precisavam ou desejavam participar; se a formação partia dos problemas enfrentados por eles dentro de sala de aula; se sentiam que os colegas se interessavam por terem uma formação continuada; e se, caso a formação não viesse acontecendo do modo desejado, quais seriam os problemas que a impediam de ocorrer e quais as possibilidades para que aconteça de fato.

Paralelamente, foi realizada uma pesquisa bibliográfica por meio de um levantamento e análise das contribuições teóricas relativas à temática em questão, a fim de compreender as diferentes concepções e como vem sendo efetivada esta formação nas escolas nas últimas décadas, para que, em posse dos dados coletados em campo e com a pesquisa bibliográfica, fosse possível identificar os desafios e as possibilidades para efetivá-la. Assim, foi proposto, junto aos professores e à equipe pedagógica, a elaboração de um plano de ação que considerasse a realidade escolar e as possibilidades de transformação das práticas pedagógicas sem negar as dificuldades, mas avançando nos campos possíveis para implantar a formação continuada dentro do espaço escolar, em que sirva para auxiliar o professor em sua prática pedagógica. 


\section{A FORMAÇÃO CONTINUADA DOS PROFESSORES NO ESPAÇO ESCOLAR: ALGUMAS REFLEXÕES}

A seguir, apresentaremos o perfil dos profissionais da educação que colaboraram com a pesquisa e os resultados deste estudo. Para tanto, primeiramente relatamos as respostas dadas pelos participantes da pesquisa nos questionários e nas entrevistas e, depois, descrevemos os encontros realizados para estudo da temática e construção do plano de ação para a formação continuada dos professores.

Para compreender e conhecer melhor os participantes da pesquisa, buscou-se, primeiramente, obter dados relativos às suas formações iniciais e continuada. Ao serem questionados sobre terem mantido uma formação continuada após o término da formação inicial, a maioria dos professores respondeu que mantinha, mas esta formação aconteceu fora do espaço escolar e por suas próprias expensas. Cabe ressaltar que, quando eles se referem à formação, estão falando de cursos de pós-graduação lato sensu.

Quando indagados sobre a frequência com que participavam de curso formação e se recebiam algum tipo de formação oferecida pelo poder público, a maioria respondeu que participava menos de uma vez por ano. Percebeu-se, na fala dos professores, que estão se referindo à formação continuada como sendo os cursos de capacitação oferecidos pela Secretaria de Educação do Estado de Rondônia. Questionados sobre os cursos oferecidos serem em suas áreas de formação, apenas os professores de Língua Portuguesa e Matemática responderam que os cursos correspondiam a suas áreas.

Os professores disseram não haver continuidade dos poucos cursos oferecidos, que geralmente só contemplam os professores de Língua Portuguesa e Matemática e que tudo acontece de maneira improvisada, não há organização ou planejamento para que se realize uma formação que leve em conta o tempo, o espaço e o contexto social vivenciados por eles. Neste sentido, tanto Libâneo (2004) quanto Gadotti (2011) asseveram que a descontinuidade dos cursos de formação continuada e, consequentemente, das políticas públicas para esse setor, como também a improvisação, é um dos problemas que impedem a efetivação da formação continuada dentro do espaço escolar.

Questionados sobre sentirem que os colegas se interessavam de ter uma formação continuada, disseram que a maioria tem interesse, mas muitos estão desanimados em relação à profissão e isso faz com que deixem de acreditar no sistema de ensino.

E os problemas não são somente esses. Os professores alegam que são muitos os problemas que impedem que a qualificação aconteça de fato e que não eram consultados sobre quais tipos de cursos precisavam ou desejavam participar. Entre os problemas por eles citados, destacam-se: a carga horária excessiva, jornada dupla ou tripla de trabalho para compensar os baixos salários, falta de incentivo financeiro, falta de profissionais capacitados para organizar, planejar e gerenciar os programas, problemas estruturais e falta de interesse dos governantes e de alguns professores que não lutam por seus direitos. Vejamos as falas de uma professora de Biologia e uma professora de Artes aqui, respectivamente, representadas pelas iniciais PB (professora de Biologia) e PA (professora de Artes):

Primeiro o professor tem uma carga horária extensa; segundo, quando tem um curso, é fora da realidade dos problemas escolares enfrentados pelo professor e as pessoas que ministram os cursos não conhecem a realidade da escola. Há uma falta de incentivo porque o governo só se preocupa com números e os cursos são mal organizados. (PB) 
A formação não acontece como deveria acontecer. Deveria ter momentos de reflexão por disciplina. Há falta de material, falta estímulo psicológico e financeiro. O professor deveria ter menos aula em sala, um salário condizente com as necessidades materiais do dia a dia. (PA)

Também a equipe pedagógica comunga do mesmo pensamento em relação aos problemas que contribuem para a não efetivação da formação continuada dentro do espaço escolar. Segundo membros da equipe, os problemas mais graves são a carga horária excessiva da maioria dos professores, a falta de incentivo financeiro, o fato de os cursos não serem focados nas áreas de formação dos professores e a falta de tempo devido à dupla e tripla jornada de alguns docentes. "A desvalorização dos profissionais, as formações que não são bem organizadas e às vezes isso não possibilita a participação dos professores nos cursos, e outro problema é a carga horária excessiva" (diretora da escola).

Oportuno se toma dizer que os problemas apontados pelos professores e pela equipe pedagógica são os mesmos já anotados por Imbernón (2009; 2011), Nóvoa (2001), Gatti e Barreto (2009) e Gadotti (2011). O professor se sente desvalorizado e desmotivado. Segundo Nóvoa (2009), há excesso nos discursos políticos para esconder a pobreza das práticas políticas para a educação.

São muitos os entraves que impedem que a formação continuada aconteça de modo efetivo dentro do espaço escolar. Isso fica evidenciado nas falas dos professores, que reclamam da falta de apoio do poder público para o exercício da profissão.

Posta assim a questão, é possível afirmar que os poucos cursos que são oferecidos, além de não terem uma continuidade e serem muitas vezes mal planejados, não partem dos problemas vivenciados pelos professores. Na fala dos professores, a formação continuada deve acontecer dentro da escola a partir de problemas específicos enfrentados pelos professores, porque são eles que devem ter habilidades específicas para lidar com as divergências do dia a dia em sala de aula.

Cumpre ressaltar que os professores e equipe pedagógica têm consciência dos problemas relativos à não efetivação da formação continuada e isso se torna mister, já que o primeiro passo para a resolução dos problemas é ter consciência deles. Desta feita, conhecendo os problemas e trabalhando em equipe, é possível promover algumas mudanças necessárias para a educação.

\subsection{Estudos sobre formação continuada e elaboração de um plano de ação para a formação continuada}

Cada escola é única, visto que atende a uma clientela específica, faz parte de um contexto social de uma determinada região e apresenta características próprias. Deste modo, para formular um plano de ação que realmente funcione para uma determinada escola e para um determinado público, é preciso conhecer essa escola e esse público-alvo.

Os problemas que permeiam o universo da formação continuada afetam de maneira diferente cada professor, chegando ao ponto de alguns profissionais não se interessarem mais em estudar. Isso pôde ser constatado durante a pesquisa, pois, segundo os professores, grande parte dos seus colegas de profissão não demonstra interesse em ter uma qualificação: uns, por já estarem perto de se aposentar, não veem mais motivos para continuar estudando; outros afirmam que os cursos não contemplam a realidade vivida por eles; outros não têm interesse devido à falta de incentivo financeiro; e outros, porque têm jornada tripla de trabalho, tendo de ministrar grande quantidade de aulas por semana, com consequente falta de tempo para estudar. 
Mesmo havendo esse desinteresse por parte de alguns professores, a maioria deles garante ter alguma dificuldade no desenvolvimento de suas práticas pedagógicas pela falta de formação continuada. Essas dificuldades estão relacionadas à falta de atualização, de trabalhar de maneira mais lúdica e de conhecer novas metodologias, bem como ao fato de lidar com situações-problema causadas pelos alunos e lecionar para alunos com necessidades educacionais especiais.

Entretanto os professores afirmam não serem ouvidos e não participam das decisões sobre sua formação. Chegaram a afirmar que a formação continuada não acontece da forma como deveria acontecer. Isso é, se é possível dizer que existia algum tipo de formação, já que eles entendem que não há nenhum tipo na escola em que trabalham. Esta denúncia feita pelos professores é algo muito grave, pois, como afirma Nóvoa (2001, p. 12), curso de formação continuada "deve se concentrar em dois pilares: a própria pessoa do professor, como agente, e a escola, como lugar de crescimento profissional permanente". A instituição escolar não pode se eximir em auxiliar o professor em sua formação.

A equipe pedagógica reconhece que não existe uma formação continuada propriamente dita na escola e os cursos esporádicos que são oferecidos não partem dos problemas enfrentados pelos professores em sala de aula. Também afirmou que é realizado um levantamento para saber direcionar cursos de formação junto aos professores.

Quando se perguntou à equipe pedagógica se a formação deveria partir de problemas gerais da educação ou de problemas específicos enfrentados pelos professores em sala de aula, tanto professores como equipe pedagógica responderam que os cursos de formação continuada deveriam partir dos problemas específicos enfrentados por eles, para então atingir os problemas macro da educação, visto que somente é possível resolver os problemas gerais se os específicos são resolvidos gradativamente. Assim, os cursos de formação deveriam acontecer dentro do espaço escolar, partindo dos problemas enfrentados pelos professores.

A equipe pedagógica mostra-se confiante e diz que, apesar dos problemas já apontados pelos professores, é possível realizar a formação continuada no espaço escolar desde que todos estejam dispostos a participar; pode-se construir um plano de ação que vise articular os meios e organizar os modos para efetivá-lo no espaço escolar.

Desta forma, foi proposto aos participantes da pesquisa que fossem promovidos três encontros de estudo e discussão coletiva sobre o tema. As discussões promovidas durante o desenvolvimento deste estudo serviriam para que os professores e a equipe pedagógica pudessem conhecer melhor as diversas concepções de formação continuada trazidas por diferentes autores, para que pudessem falar sobre os problemas e as dificuldades enfrentados em sala de aula e apontarem possíveis meios para efetivar a formação dentro do espaço escolar.

O intuito desses momentos de discussão também foi para criar um ambiente de colaboração, pois, como assevera Perrenoud (2001), a maioria dos professores que estão em exercício foi formada numa perspectiva individualista, não sendo formados para trabalhar em grupo, mas para atuarem numa sala de aula onde ele é o professor e os demais são alunos. Porém a profissão não é uma aventura solitária, visto que a educação se faz em conjunto. Assim, professores, alunos e demais profissionais que atuam na escola devem trabalhar em sintonia para que a aprendizagem e o desenvolvimento intelectual do aluno aconteçam.

No mesmo sentido, Imbernón (2009) afirma que a formação continuada do professor necessita de um ambiente de colaboração entre os professores, em que todos realmente desejem participar, já que não é possível mudar aquele que não quer uma mudança. É preciso minimizar 
as diferenças e aceitar a diversidade, assim, é necessário fomentar diferentes reflexões, buscando pontos conexos e a compreensão dos pontos controversos. Claro que isso não é o suficiente para sanar os problemas da formação continuada, pois é preciso apoio externo, ou seja, apoio dos administradores estaduais por meio de políticas públicas adequadas que visem à melhoria da educação e à qualificação do professor.

No primeiro encontro, discutiu-se sobre os problemas que impedem que a formação continuada aconteça dentro do espaço escolar e, ao mesmo tempo, apontaram-se possíveis formas para que a efetivação dessa formação aconteça de fato.

Os problemas apresentados durante os momentos de discussão foram os mesmos já mencionados pelos questionários e entrevistas. E, em relação aos possíveis meios para efetivação da formação continuada nesta escola, tanto aos professores como a equipe pedagógica deram suas contribuições. Primeiro foi dito que era preciso organizar bem o tempo, ter a participação de todos, partir dos problemas da escola, promover momentos de discussão e troca de experiências e fazer parcerias para trazer pessoas especializadas nos assuntos que forem escolhidos como necessários para a formação. De acordo com eles, apesar de os problemas, com a devida organização e planejamento, é possível efetivar a formação continuada dentro desta escola.

Cabe ainda salientar que, neste encontro, foram discutidos conceitos de formação trazidos pelos autores que serviram de base ao referencial teórico para o desenvolvimento do estudo de pesquisa-ação proposto pelas pesquisadoras.

Os professores também exprimiram no decorrer da reunião a dificuldade de se trabalhar coletivamente e indicaram os possíveis motivos: novamente, a falta de tempo, o fato de não terem sido formados nessa perspectiva e os empecilhos pessoais.

O trabalho em equipe, coletivo ou colaborativo não é tarefa fácil, mas é possível quando todos estão dispostos a crescer juntos. Como corrobora Imbernón (2011), as pessoas não aprendem de modo linear e cada pessoa aprende de uma forma diferente; deste modo, o processo de ensino e aprendizagem é algo complexo, entretanto essa complexidade se torna mais amena quando a formação é contextualizada e se adapta à realidade vivenciada pelo professor. Então, alguns professores disseram que seria possível efetivá-la dentro desta escola.

No segundo encontro foi elaborado de forma coletiva um esboço do plano de formação continuada específico, visando sua efetivação para os professores que atuam naquela escola, um plano que contemple as necessidades e especificidades dos professores e da escola.

Primeiramente, foi pensado em organizar os horários de planejamento por área de formação para que os professores pudessem usar este tempo para troca de experiências e refletir sobre os problemas que enfrentam na vida profissional como um todo, ou seja, os problemas dentro de sala de aula e externos à sala, mas que afetam a vida do profissional.

Depois se discutiu a necessidade de se ter um profissional dentro da escola que seja responsável para atuar junto aos professores, organizar reuniões, oficinas, palestras e outros eventos que sirvam de formação para os professores. Após a discussão, ficou decidido que essa função seria da supervisora. Assim, caberia a ela a coordenação geral das ações do plano. Foi reivindicado que tais cursos fossem ministrados no tempo destinado a estudos e à formação continuada, previstos no plano de carreira, cargos e remuneração dos profissionais da educação básica do Estado de Rondônia, isto porque qualquer tempo além da carga horária de 40 horas semanais cumpridas na rede estadual comprometeria os outros empregos - uns na rede municipal 
de ensino, outros em escolas particulares e outros que fazem algum tipo de serviço autônomo para complementar o salário.

Buscando atender as especificidades da escola e as reivindicações dos professores, foi elaborado um rascunho para o plano de ação e foi decido que seria realizada uma reunião com todos os professores e a equipe pedagógica para decidir quais seriam os temas e assuntos que deveriam ser trabalhados em oficinas e palestras durante o primeiro semestre do ano letivo. Também foi proposta a ação de montar os horários destinados ao planejamento por área de conhecimento, para poder facilitar a troca de experiência entre os professores, o planejamento coletivo e o acompanhamento da supervisora nessas atividades. Para tanto, o quadro de distribuição e horários de aulas deveriam ser montados procurando adequar os horários de cada professor.

Durante o segundo encontro, os professores e equipe pedagógica iam pensando e repensando possibilidades para se efetivar um plano de formação na escola, que ia sendo construído, em linhas gerais, a partir do que estava sendo definido no momento. Via-se, já, um esboço de um plano de formação continuada.

Conforme as ações definidas, foi decidido que será realizada uma oficina por bimestre e por área de conhecimento, uma palestra por bimestre sobre um tema geral da educação, planejamento coletivo com os professores de áreas afins duas vezes ao mês e uma reunião pedagógica por semestre para discutir sobre as ações realizadas e a formação continuada.

No terceiro encontro, foi apresentado o plano de formação continuada pré-elaborado nos encontros anteriores para os ajustes finais e necessários. Após a apresentação do plano, alguns professores pediram a palavras e, a partir disso, foram feitos alguns ajustes no plano.

Foi muito gratificante perceber o entusiasmo dos professores naquele momento. Alguns professores expressaram isso de maneira enfática. Segundo eles, o plano de ação com planejamento coletivo é uma necessidade da escola e essa é uma necessidade que não cessa, pois a formação é contínua.

Percebe-se, aqui, que os professores têm compromisso com a formação e o que lhes falta são as oportunidades, pois reconhecem e assumem a responsabilidade da formação continuada como um compromisso de suas profissões.

Desta forma, construiu-se coletivamente um plano de formação continuada que foi pensado e efetivado pelos professores e pela equipe pedagógica da escola. Segundo os docentes, as experiências de discussões sobre o tema em tela e as reflexões que puderam fazer sobre suas próprias práticas pedagógicas foram muito ricas e este estudo mostrou-lhes que é possível se organizar coletivamente e desenvolver formação permanente dentro do espaço escolar.

\section{CONSIDERAÇÕES FINAIS}

Efetivar a formação continuada dentro do espaço escolar não é uma tarefa simples devido aos vários empecilhos demonstrados neste estudo. Entretanto esses podem ser contornados desde que escola, professores e demais profissionais da educação estejam dispostos a participar desse processo. No entanto não há uma receita pronta para se efetivar a formação continuada. Os planos de ação já existentes devem servir como apontamentos para reflexão e análise e, então, a partir desse norte, compreender a realidade da escola e vivenciar a dinâmica do processo de aprendizagem e as peculiaridades de cada escola. 
Um dos elementos que também auxiliaram na elaboração do plano de ação foi ver a escola como instituição principal no desenvolvimento do processo de formação continuada do professor. É na escola que as transformações se iniciam e é na escola que estão os principais envolvidos no processo educativo. Buscou-se um modelo de formação centrado na escola por se entender, no decorrer do estudo, que é o que melhor atendia as necessidades e especificidades tanto dos professores como da escola.

Vimos que vários estudos desenvolvidos pelos autores já mencionados têm demonstrado uma significativa preocupação com a importância e a garantia da efetivação da formação continuada, e grande parte desses estudos aponta para uma formação desenvolvida a partir da escola. Porém acreditamos que são necessárias alterações nas políticas públicas de formação. Essas precisam ser repensadas a fim de que as escolas tenham autonomia para que possam minimizar os problemas apontados como empecilhos no desenvolvimento de projetos de formação continuada dentro da escola.

Mister se faz destacar que entendemos também que, mesmo que as escolas consigam efetivar a formação continuada para seus professores dentro do espaço da escola, isso não exime a responsabilidade do Estado em promover e oferecer cursos de formação, em nível de aperfeiçoamento e de especialização (pós-graduação lato sensu), de forma gratuita para docentes em exercício.

Não queremos, neste texto, apresentar receita nem modelos de formação para serem copiados, mas buscamos apresentar propostas viáveis para que a formação possa acontecer dentro do espaço da escola. O plano elaborado foi pensado e discutido especificamente para a realidade da escola pesquisada e dos professores que nela trabalham; foi fundamentado nos autores e autoras estudados e já citados neste estudo.

O esforço das pesquisadoras e dos membros da escola, participantes do estudo, fez com que se chegasse a uma proposta de um plano de ação de formação continuada fundado na reflexão-ação da própria prática pedagógica, com a possibilidade de melhorá-la, alterá-la, modificá-la qualitativamente, considerando principalmente os problemas, dificuldades e possibilidades que permeiam o ambiente escolar daquela escola em específico e os aspectos relacionados à qualidade na educação de maneira geral.

Nosso esforço e nossa crença foram colocados no estudo e esperamos que seus resultados, descritos sinteticamente neste texto, possam contribuir para com outras escolas em suas especificidades.

\section{REFERÊNCIAS}

AZZI, Sandra. Trabalho docente: autonomia didática e construção do saber pedagógico. In: PIMENTA, Selma Garrido (Org.). Saberes pedagógicos e atividade docente. 2. ed. São Paulo: Cortez, 2000. p. 35-60.

BRASIL. Ministério da Educação. Referenciais para a formação de professores. Brasília, 2002. Disponível em: http://www.dominiopublico.gov.br/download/texto/me000511.pdf . Acesso em: 22 fev. 2017.

BRASIL. Lei Ordinária 9.394, de 20 de dezembro de 1996. Lei de Diretrizes e Base da Educação Nacional. Disponível em: http://www.planalto.gov.br/ccivil_03/leis/l9394.htm. Acesso em: 20 fev. 2017.

FREIRE, Paulo. Pedagogia da autonomia: saberes necessários à prática educativa. São Paulo: Paz e Terra, 2011. 
GADOTTI, Moacir. Boniteza de um sonho: ensinar-e-aprender com sentido. 2. ed. São Paulo: Instituto Paulo Freire, 2011.

GATTI, Bernadete Angelina; BARRETO, Elba Siqueira de Sá (Coord.). Professores do Brasil: impasses e desafios. Brasília: UNESCO, 2009.

GIL, Antônio Carlos. Métodos e técnicas da pesquisa social. 5. ed. São Paulo: Atlas, 1999.

IMBERNÓN, Francisco. Formação docente e profissional: forma-se para a mudança e a incerteza. Tradução Silvana Cobucci Leite. 9. ed. São Paulo: Cortez, 2011.

IMBERNÓN, Francisco. Formação permanente do professorado: novas tendências. Tradução Sandra Trabucco Valenzuela. São Paulo: Cortez, 2009.

LIBÂNEO, José Carlos. Organização e gestão da escola - teoria e prática. Goiânia: Alternativa, 2004.

MARQUES, Mario Osorio. A formação do profissional da educação. ljuí, RS: Ed. UNIJUI, 2000.

NÓVOA, António. Para una formación de profesores construida dentro de la profesión. Revista de Educación, n. 350, p. 203-18, set./dez. 2009.

NÓVOA, António. O professor se forma na escola. Nova Escola, n. 142, 2001.

PRADA, Luis Eduardo Alvarado. Dever e direito à formação continuada de professores. Revista Profissão Docente, Uberaba, MG, v. 7, n. 16, p. 110-23, ago./dez. 2007.

PEREIRA, Júlio Emílio Diniz. Formação de professores - pesquisa, representações e poder. 2. ed. Belo Horizonte: Autêntica, 2007.

PERRENOUD, Philippe. Ensinar: agir na urgência. Decidir na incerteza. Tradução Cláudia Schilling. 2. ed. Porto Alegre: Artemed, 2001.

PERRENOUD, Philippe. Dez novas competências para ensinar. Tradução Patrícia Chittoni Ramos. Porto Alegre: Artmed, 2000.

PIMENTA, Selma Garrido. Formação de professores: identidade e saberes da docência. In: PIMENTA, Selma Garrido (Org.). Saberes pedagógicos e atividade docente. 2. ed. São Paulo: Cortez, 2000. p. 15-34.

RODRIGUES, Neidson. Da mistificação da escola à escola necessária. 8. ed. São Paulo: Cortez, 1998.

RONDÔNIA. Lei Complementar n. 680, de 7 de setembro de 2012. Disponível em: http://ditel.casacivil. ro.gov.br/COTEL/Livros/Files/LC680.pdf. Acesso em: 22 fev. 2017.

SANTOS, Carmi Ferraz. O ensino da leitura e a formação em serviço do professor. Revista Teias, Rio de Janeiro, ano 3, n. 5, p. 29-34, jan./jun. 2002.

SILVA, Everson Melquiades Araújo. Dispositivos metodológicos para a formação continuada de professores: uma abordagem crítico-reflexiva. In: FERREIRA, Tereza Brito; ALBUQUERQUE, Eliana Borges Correia; LEAL, Telma Ferraz (Org.). Formação continuada de professores: questões para reflexão. Belo Horizonte: Autêntica, 2007. p. 97-118.

THIOLLENT, Michel. Metodologia da pesquisa-ação. 14. ed. São Paulo: Cortez, 2005. 


\section{Sobre as autoras:}

Sirley Leite Freitas: Doutoranda em Educação pelo Programa de Pós-Graduação em Educação da Faculdade de Filosofia e Ciências, da Universidade Estadual Paulista (UNESP). Mestre em Educação Escolar pelo Programa de Mestrado Profissional em Educação Escolar pela Fundação Universidade Federal de Rondônia (UNIR). Graduada em Pedagogia pela UNIR e em Direito pelo Centro Luterano de Ji-Paraná. Professora do Instituto Federal de Rondônia (IFRO) na área de Pedagogia. Tem experiência nas áreas de Educação e Direito, com ênfase em formação docente, legislação educacional, políticas públicas educacionais, psicologia da educação, avaliação da aprendizagem, direito constitucional, atuando principalmente nos seguintes temas: políticas públicas educacionais; formação docente; legislação educacional, psicologia da educação, avaliação da aprendizagem, ética e cidadania. E-mail: sirleitefreitas@gmail.com, Orcid: http://orcid.org/0000-0003-0446-135X

Juracy Machado Pacífico: Doutora em Educação Escolar pela Universidade Estadual Paulista (UNESP). Mestre em Psicologia Escolar pela Universidade de São Paulo (USP). Graduada em Pedagogia pela Universidade Federal de Rondônia (UNIR). Professora da UNIR, com atuação no Curso de Licenciatura em Pedagogia. A partir de 2013, passou a atuar também no PPGEE/ MEPE, do qual é coordenadora. Coordena e supervisiona o Estágio Curricular Supervisionado em Educação Infantil no Curso de Pedagogia da UNIR desde o ano de 2014. Tem experiência na área de Educação, atuando nos seguintes temas: infância; educação infantil; políticas públicas educacionais; gestão escolar; formação docente; alfabetização. É membro associada da ANPED, participante do GT07. E-mail: juracypacifico@unir.br, Orcid: http://orcid.org/0000-0003-0486-874X 
